\title{
MUDIK DALAM PERSPEKTIF BUDAYA DAN AGAMA (Kajian Realistis Perilaku Sumber Daya Manusia)
}

\author{
Abdul Hamid Arribathi ${ }^{1}$ \\ Qurotul Aini ${ }^{2}$ \\ Dosen STMIK Raharja ${ }^{1,2}$ \\ Jl. Jendral Sudirman No. 40, Modern Cikokol, Tangerang ${ }^{1,2}$ \\ Email : abdulhamid@raharja.info ${ }^{1)}$,aini@raharja.info ${ }^{2)}$
}

\begin{abstract}
ABSTRAK
Lebaran Idul Fitri identik dengan mudik, menjadi kebutuhan dan seolah kewajiban yang jika ditinggalkan akan berdosa bahkan terasa ada sesuatu yang hilang. Padahal mudik tidak dikenal dalam ajaran Islam. Dengan kata lain mudik asli tradisi dan budaya Indonesia. Permasalahan : apakah budaya mudik sejalan dengan ajaran Islam dan benarkah Islam datang untuk menghancurkan budaya lokal ?. Tulisan ini bertujuan memberi penjelasan dan menyakinkan kepada pembaca bahwa mudik itu asli budaya Indonesia, namun tetap sesuai dengan ajaran Islam dan Islam datang bukan untuk mengikis dan mengahancurkan budaya lokal, namun untuk meluruskan. Penelitian ini merupakan penelitian hukum normative yang bersifat deskriptif. Metode yang digunakan metode yuridis normatif. Sumber data sekunder yang digunakan mencakup bahan hukum primer, bahan hukum sekunder dan bahan hukum tersier. Data yang diperoleh kemudian dipilah-pilah guna memperoleh data, ayat dan hadist yang berkaitan dengan kaidah hukum yang kemudian dihubungkan dengan permasalahan yang dihadapi dan disistematisasikan sehingga menghasilkan klasifikasi yang selaras dengan permasalahan dalam penelitian ini. Selanjutnya bahan hukum yang diperoleh diolah secara deduktif kualitatif untuk sampai pada kesimpulan, sehingga pokok permasalahan yang ditela'ah dalam penelitian ini akan dapat dijawab.
\end{abstract}

Kata Kunci : Mudik, Budaya dan Agama.

\begin{abstract}
Idul Fitri is synonymous with homecoming, becomes a necessity and as if obligations which if left will be sinful and there is something missing. Yet mudik not known in Islamic teachings. In other words mudik original traditions and culture of Indonesia. The problem: is the culture of going home in accordance with the teachings of Islam and is it true Islam came to destroy the local culture ?. This paper aims to explain and convince the reader that the homecoming is original Indonesian culture, but still in accordance with the teachings of Islam and Islam came not to erode and destroy the local culture, but to straighten. This study is a normative legal research that is descriptive. The method used by the normative juridical method. Secondary data sources used include primary legal materials, secondary law materials and tertiary legal materials. The data obtained are then sorted to obtain data, verses and hadiths related to the rule of law which are then connected with problems encountered and systematized so as to produce a classification in harmony with the problems in this study. Furthermore, the legal material obtained is processed by deductive qualitative to arrive at the conclusion, so that the subject matter studied in this research will be able to be answered.
\end{abstract}

Keywords: Mudik, Culture and Religion.

\section{PENDAHULUAN}

Mudik merupakan fenomena sosio-kultural. Dia adalah darah daging manusia Indonesia. Berbagai alasan rasional seolah tidak mampu menjelaskan fenomena yang teranyam rapat dalam nilai kultural bangsa Indonesia itu. Pulang mudik sekali setahun tidak hanya sekedar melepas kerinduan pada kampung halaman tetapi mengandung makna yang jauh lebih dalam dari itu. Kalau hanya sekedar mengobati kerinduan pada keluarga atau 
kampung halaman, tentu dapat dilakukan di lain waktu, di luar waktu lebaran. Dan untuk itu tidak perlu bersusah payah mencucurkan keringat di perjalanan. Tetapi toh orang tidak melakukannya. Lihatlah setiap tahun jumlah pemudik terus saja membanjiri terminal, stasiun, pelabuhan, hingga bandara. Berdasarkan data lebaran 2013 diperkirakan 24 juta pemudik bergerak menuju kampung halaman. Jumlah yang setara dengan $90 \%$ penduduk Malaysia. Sedangkan jumlah pemudik lebaran yang terbesar dari Jakarta adalah menuju Jawa Tengah. Secara rinci prediksi jumlah pemudik tahun 2014 ke Jawa Tengah mencapai 7.893.681 orang. Dari jumlah itu didasarkan beberapa kategori, yakni 2.023.451 orang pemudik sepeda motor, 2.136.138 orang naik mobil, 3.426.702 orang naik bus, 192.219 orang naik kereta api, 26.836 orang naik kapal laut, dan 88.335 orang naik pesawat. Dan ini terus akan meningkat setiap tahunnya. Mengapa demikian ?.

Memang ada berbagai alasan mengapa orang balik mudik lebaran. Namun, fenomena mudik jelas berkaitan erat dengan alasan kultural yang menyangkut tiga hal pokok, yaitu kebutuhan kultural untuk mengunjungi orang tua dan keluarga, berziarah ke makam kerabat, dan menilik warisan tinggalan keluarga di tempat asal. Jika ketiga alasan itu tidak hadir, maka dapat dipastikan dorongan untuk mudik menjelang lebaran hampir tidak ada. Namun yang paling pokok dari ketiga hal itu tampaknya adalah alasan untuk mengunjungi orang tua dan kerabat. Pada bangsa Indonesia, umumnya ada semacam kebutuhan kultural yang seolah-olah sebuah kekuatan yang mampu "memaksa" para perantau pulang kampung untuk mengunjungi orang tua dan kerabat mereka pada saat lebaran. Kebutuhan kultural itu begitu kuatnya dan mendorong orang untuk pulang mudik. Dorongan itu semakin kuat dengan adanya persepsi bahwa kesempatan yang paling cocok dan pantas bagi anak-anak terhadap orang tua. Hal inilah yang melatarbelakangi penulis membahas judul: " Mudik dalam perspektif Budaya dan Agama".

\section{PERMASALAHAN}

Agar lebih spesifik dalam penulisan ini. Dirumuskan masalah sebaigai berikut : Bagaimana asal-usul dan sejarah mudik ?, apakah budaya mudik sejalan dengan ajaran Islam dan benarkah Islam datang untuk menghancurkan budaya lokal ?.

Mengingat mudik dapat ditinjau dari berbagai aspek, maka agar lebih fokus penulis membatasi dalam dua aspek, yaitu budaya dan agama (ajaran Islam).

\section{PEMBAHASAN}

\section{Arti dan Sejarah Budaya Mudik Di Indonesia.}

Setiap menjelang hari raya Idul Fitri, hampir seluruh media massa baik cetak dan eletronik mulai menyoroti aktivitas mudik, bahkan pemerintah khususnya kementrian perhubungan dan kepolisian dikerahkan untuk mensukseskan kegitan ini, sebab setiap tahun jumlah pemudik terus saja membanjiri terminal, stasiun, pelabuhan, hingga bandara. Lalu dari mana sebenarnya asal muasal istilah mudik ?. Jelasnya, tidak ada yang dapat menjawab secara pasti. Istilah kata mudik secara bahasa tercatat di Kamus Besar Bahasa Indonesia ( Pusat Pembinaan dan Pengembangan Bahasa Departemen Pendidikan Dan Kebudayaan : 1990 ), di dalam kamus tersebut mudik berarti "Pulang ke udik atau pulang ke kampung halaman bersamaan dengan datangnya hari Lebaran". Di dalam ajaran Islam, tradisi mudik tidak dikenal. Selesai melaksanakan puasa selama sebulan penuh, umat Islam hanya diperintahkan mengeluarkan zakat fitrah dan melaksanakan salat Id Fitri baik di masjid ataupun di tanah lapang, serta dilarang berpuasa pada hari satu Syawal tersebut. Namun dapat juga kata idul 
fitri apabila ditinjau dari segi bahasa dapat diartikan kembali suci atau kodrat sebagai kembali kepada asal muasal. Dari asal kata Arab "Aada-ya'uudu-'audan( عَادَ- يعود-عَوْدًا ) yang bermakna kembali, dan fitrah ( فِطْرة ( فِ ( ) yang bermakna suci atau kodrat (asal muasal) atau futhur ( فُطُور ) yang bermakna makan pagi (Mahmud (Mahmud Yunus : ). Sehingga secara filosofi dapat dimaknai para perantau di kota-kota besar berondong-bondong kembali ke kampung halamannya (asal muasal) atau dikenal mudik. Sementara menurut Umar Kayam (2002), mudik awal mulanya merupakan tradisi primordial masyarakat petani Jawa. Keberadaannya jauh sebelum kerajaan Majapahit. Awalnya kegiatan ini digunakan untuk membersihkan pekuburan atau makam leluhur, dengan disertai doa bersama kepada dewadewa di Khayangan. Tradisi ini bertujuan agar para perantau diberi keselamatan dalam mencari rezeki dan keluarga yang ditinggalkan tidak diselimuti masalah. Namun, sejalan masuknya pengaruh ajaran Islam ke tanah Jawa membuat tradisi ini lama-kelamaan terkikis, karena dianggap perbuatan syirik terutama bagi mereka yang menyalahgunakan dengan meminta kepada leluhur yang telah meninggal dunia.

Fonema dan istilah mudik lebaran mengemuka kembali pada 1970-an. Saat itu, Jakarta merupakan satu-satunya kota besar di Indonesia. Orang dari desa beramai-ramai datang ke Jakarta untuk mencari pekerjaan dan mengubah nasib. untuk mereka yang sudah mendapat pekerjaan, mereka akan mendapatkan jatah libur panjang. Biasanya, libur panjang itu jatuh pada hari besar seperti Hari Raya Idul Fitri. Jadilah momen lebaran ini digunakan untuk mudik atau pulang kampung dan bersilaturahmi dengan keluarga, juga mereka selalu menyempatkan diri untuk ziarah dan membersihkan kuburan leluhur. Kini, teknologi semakin maju. Sudah ada handphone, internet, hingga teleconference yang memudahkan komunikasi dari jarak jauh. Namun, meskipun biaya komunikasi lewat handphone dan internet sudah terjangkau, masyarakat merasa tradisi mudik belum dapat tergantikan. Menurut sosiolog Universitas Gajah Mada Arie Sudjito ada beberapa hal yang menyebabkan teknologi tidak bisa menggantikan tradisi mudik. Salah satunya, disebabkan teknologi tersebut belum menjadi bagian dari budaya yang mendasar di Indonesia, terutama pada masyarakat pedesaan. Sehingga para perantau rela berdesak-desakan mengantre tiket, kereta dan pesawat hanya demi tiba di kampung halaman sebelum Lebaran. Namun, bukan berarti tradisi mudik tidak bisa hilang. Tradisi mudik bisa saja hilang, namun membutuhkan waktu yang relatif lama. Setidaknya, ada 4 hal yang menjadi tujuan orang untuk melakukan mudik dan sulit digantikan oleh teknologi. Pertama, mencari berkah dengan bersilaturahmi dengan orangtua, kerabat, dan tetangga. Kedua, terapi psikologis. Kebanyakan perantau yang bekerja di kota besar memanfaatkan momen lebaran untuk refreshing dari rutinitas pekerjaan sehari-hari. Sehingga ketika kembali bekerja, kondisi sudah fresh lagi. Ketiga, mengingat asal usul. Banyak perantau yang sudah memiliki keturunan, sehingga dengan mudik bisa mengenalkan mengenai asal-usul mereka. Dan keempat, adalah unjuk diri. Banyak para perantau yang menjadikan mudik sebagai ajang unjuk diri sebagai orang yang telah berhasil mengadu nasib di kota besar (Arie Sudjito : 2012).

\section{Negara-Negara Yang Memiliki Tradisi Mudik}

Ternyata kegiatan sejenis mudik bukan hanya di Indonesia. Namun ada beberapa negara yang melakukan tradisi sejenis mudik, walaupun dengan tujuan dan momen yang berbeda. Negara-negara tersebut, antara lain : 


\subsection{Tiongkok}

Jumlah penduduk Tiongkok untuk sekarang mencapai lebih dari satu miliar jiwa. Sekitar 18 juta penduduk memeluk agama Islam. Penduduk beragama Islam kebanyakan tinggal di Xinjiang dan Yunnan. Kedua kota itu selalu merayakan Lebaran secara meriah. Tradisi mudik di Tiongkok tidak hanya berlangsung saat lebaran saja. Pulang kampung dengan arus yang paling padat terjadi pada saat perayaan tahun baru Tiongkok, yang dikenal dengan Imlek. Perayaan Imlek di Tiongkok jauh lebih meriah dibanding Hari Raya Idul Fitri.

\subsection{Turki}

Idul Fitri di Turki dikenal dengan istilah Bayram. Saat berjumpa dengan sesama muslim selama lebaran, mereka akan saling mengucapkan salam "Bayraminiz Kutlu Olsun", "Mutlu Bayramlar", atau "Bayraminiz Mubarek Olsun". Ketiganya memiliki arti yang hampir sama yaitu selamat merayakan Hari Raya Bayram.

\subsection{India}

India adalah salah satu negara dengan jumlah penduduk terbesar di dunia di bawah Tiongkok. Negara ini juga memiliki perayaan lebaran yang meriah, meskipun jumlah umat muslimnya tergolong minoritas. Salah satu kemeriahan lebaran di India terasa saat mudik. Tetapi, arus mudik lebaran lebih kecil dibandingkan pada bulan Oktober hingga November. Saat itu, sebagian besar warga India akan merayakan "Festival of Lights alias Dilwali". Perayaan ini meriahnya sama dengan perayaan Idul Fitri di negara-negara Islam. Warga India akan berbondong-bondong pulang ke kampung halaman mereka. Pemandangan mudik di negara ini lebih heboh dibanding di Indonesia. Transportasi umum seperti kereta api akan penuh sesak hingga banyak warga yang bergelantungan di pintu, jendela hingga di atap kereta.

\subsection{Malaysia}

Negara tetangga yang masih serumpun ini juga memiliki tradisi mudik menjelang Hari Raya Idul Fitri. Sama seperti Indonesia, penduduk Malaysia mayoritas muslim. Sehingga, kemeriahaannya saat mudik lebaran sangat terasa. Mereka yang mudik adalah warga yang merantau ke kota untuk bekerja. Bedanya Malaysia tidak mengenal istilah mudik atau pulang kampung, melainkan Balik Kampung.

\subsection{Arab Saudi}

Tradisi mudik juga lakukan warga muslim di Arab Saudi menjelang Hari Raya Idul Fitri. Mengingat negara ini mayoritas penduduknya adalah muslim. Apalagi, Arab memiliki Ka'bah sebagai tempat ibadah paling suci umat Islam. Tak heran tiap lebaran, perayaannya selalu meriah sekali. Biasanya, masing-masing daerah menggelar festival yang menampilkan pagelaran teater, pertunjukan musik, dan kesenian lainnya. Keluarga yang merantau akan pulang, sedangkan anggota keluarga yang tinggal di rumah akan mendekorasi rumahnya seindah mungkin dan menyiapkan aneka masakan khas lebaran. Begitu juga dengan orangorang Maghrib (Marokko), Tunisia dan Aj-Jazair yang bekerja di negara-negara lain di Eropa, Amerika dan di negara-negara Timur Tengah sendiri, mereka juga pulang kampung atau mudik pada hari-hari baik, khususnya pada menjelang lebaran Idul Fitri. Mereka pulang mulai 
yang menggunakan pesawat terbang, kapal laut, bus, kereta api, sampai mobil dan sepeda motor, sehingga kadang-kadang jalan menjadi penuh sesak dan macet.

\section{Mudik Dalam Perspektif Budaya}

Meski ditempatkan sebagai sesuatu yang tak ada kaitannya dengan ajaran Islam namun mudik tak pernah terhapus sebagai tradisi. Mudik merupakan kenyataan yang tak bisa dipungkiri sebagai kebiasaan masyarakat muslim di Indonesia. Mudik ditempatkan sebagai bahasa budaya sementara Idul Fitri adalah bahasa agama.

Mudik merupakan bentuk sinergi antara ajaran agama dengan budaya atau tradisi masyarakat Indonesia. Sebagai sebuah tradisi mudik telah mengakar secara kuat. Sementara dalam pandangan agama berbagai tradisi dalam mudik diyakini memiliki landasan. Dengan demikian makna mudik sebenarnya tak hanya sebagai kebiasaan pulang kampung melainkan erat kaitannya dengan berbagai sifat dan dimensi kehidupan manusia.

Secara kultural mudik memang sebuah warisan atau bahkan keharusan. Tapi secara moral dan spiritual mudik juga menjadi wujud bakti anak kepada orang tua. Kebiasaan sungkeman, meminta maaf hingga berziarah mendoakan anggota keluarga yang telah tiada menunjukkan jika mudik bukan hanya perjalanan fisik namun juga rohani. Sungkeman atau cium tangan orang tua bukan hanya bentuk kontak fisik melainkan memiliki makna secara spiritual karena orang tua dapat dianggap sebagai perantara bagi seorang anak dalam mengenal Tuhan. Pada akhirnya ikatan batin dengan orang tua serta kewajiban mendoakan anggota keluarga seperti ini turut melestarikan melestarikan tradisi mudik.

Mudik juga mengukuhkan sifat manusia sebagai makhluk sosial. Silaturahmi yang terjalin selama mudik merupakan interaksi manis antara seorang manusia dengan sesamanya. Melalui silaturahmi kita diingatkan kembali bahwa seorang manusia tak akan bisa mempertahankan hidup dan kehidupannya tanpa bantuan dan interaksi dengan sesamanya. Pada akhirnya silaturahmi sebagai bagian dari mudik menjadi sarana yang sangat humanis dan interaktif untuk membangun toleransi karena mudik dan silaturahmi juga dijalankan dan dijalin oleh banyak masyarakat dari berbagai latar perbedaan termasuk agama.

\section{Mudik Dalam Perspektif Agama.}

Pertanyaannya, bagaimana perspektif syariat Islam dalam hal mudik? Adakah anjuran atau larangan soal pulang kampung tersebut?. Mudik secara etimologi adalah kegiatan perantau/pekerja migran untuk kembali ke kampung halamannya (Wikipedia ). Makna mudik

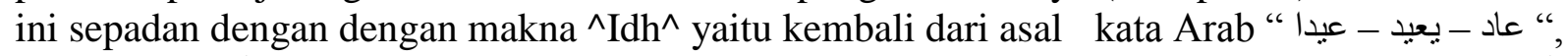
dan fitri ( الفطور / yang bermakna suci atau kesucian. Dapat juga fitri bermakna futhur (makan pagi-pagi) sebab masyarakat muslim dibolehkan kembali makan di pagi hari setelah sebulan menjalankan puasa/siyam bulan Ramadhan. Dalam hal ini, mudik jika dicermati satu firman Allah SWT berikut: "Sembahlah Allah dan janganlah kamu persekutukan-Nya dengan sesuatupun. Dan berbuat baiklah kepada dua orang ibu-bapa, karib-kerabat, anak-anak yatim, orang-orang miskin, tetangga yang dekat dan tetangga yang jauh, teman sejawat, ibnu Sabil dan hamba sahayamu. Sesungguhnya Allah tidak menyukai orang-orang yang sombong dan membangga-banggakan diri." (QS. An-Nisa': 36. Dalam ayat tersebut di atas, Allah SWT dengan jelas dan tegas memerintahkan kepada kita untuk berbuat baik kepada orang tua, karib kerabat, tetangga, teman sejawat dan seterusnya. Dan ini menjadi satu kewajiban bagi semua 
hamba yang beriman dan bertakwa kepada Allah (Quraish Shihab :2007). Berbuat baik dimaksudkan antara lain dengan mudik untuk bertemu, bersalaman guna saling memaafkan dan sampai-sampai melepas kerinduan melalaui momen lebaran .Tidak itu bagi pemudik biasanya membawa pulang sejumlah uang dan barang sebagai hasil jerih payahnya selama di perantauan. Pemudik yang baik, biasanya tidak hanya diperuntukkan bagi keluarga utamanya saja, tetapi juga dia berbagi untuk keluarga dekat, tetangga dan teman sejawat dan seterusnya. Biasanya malah ada yang mengadakan kenduri yaitu bentuk syukur nikmat dan bersedekah dengan lebih luas dan merata kepada masyarakatnya atas limpahan rejeki yang telah diberikan Allah SWT. Semua itu menjadi daya tarik dan kebanggaan sendiri bagi pemudik, calon perantau lain dan keluarganya. Dari sisi lain lagi, dapat dilihat mudik sebagai upaya menyambung dan mempererat hubungan silaturrahim. Setelah sekian lama mereka tidak bertemu, tidak ngumpul dan tidak melakukan tukar informasi, maka dengan mudik tali silaturrahim akan tersambung. Lebih-lebih bagi orang yang paham akan pentingnya bersilaturrahim, yaitu akan dilapangkan rezekinya dan dipanjangkan umurnya, maka pilihan untuk mudik menjadi lebih bermakna dan berguna bagi kehidupan seseorang. Hal ini sebagaimana sabda Nabi Muhammad SAW : "Dari Anas ra, bahwasanya Rasulullah SAW bersabda: Barang siapa yang ingin dilapangkan rezekinya dan dipanjangkaan umurnya, maka hendaklah ia suka bersilaturrahmi." (HR. Bukhari dan Muslim). Dari penjelasan ini, jelaslah bahwa dalam perspektif budaya, mudik menjadi tradisi yang terus eksis dan disukai oleh umat Islam dewasa ini. Pada sisi lain, dalam sudut pandang syari'at Islam mudik, paling tidak berhubungan dengan prinsip berbuat baik dan bersilaturrahim, adalah hal-hal yang dianjurkan dalam syariat Islam. Dengan mudik seseorang dapat mengaplikasi bentuk pengabdian dan berbuat baiknya kepada orang tua, anggota keluarga, dan kerabat lainnya. Kemudian dengan mudik pula hubungan silaturrahmi yang selama ini mungkin sudah renggang, dapat terajut kembali dengan baik.

Dalam tinjauan psikologi hakekatnya manusia cinta dan butuh mudik, yaitu manusia mencintai dan membutuhkan nilai-nilai dasar luhur kemanusiaan seperti : butuh dimaafkan, ingin memaafkan, menyayangi-disayangi, menerima dan berbagi serta kumpul bersama. Dan inilah menjadi kebutuhan dasar fisiologis manusia (Maslow : Kebutuhan Manusia) yang tidak akan luntur terkikis waktu sepanjang kehidupan manusia ada. Jika semangat mudik didasari niat dan dimaknai hal tersebut di atas, maka tidak bertentangan, justru sejalan dengan ajaran Islam, bahkan Islam garda terdepan dalam mendengungkan dan memerintahkan mengamalkan ajaran berikut :

\subsection{Saling memaafkan (Anti Balas Dendam)}

Islam melarang pemeluknya memilki sifat balas dendam dan permusuhan yang akan berakibat jatuh korban dan menimbulkan pertumpahan darah. Untuk mencegah hal tersebut diperlukan ishlah (damai) dengan jalan saling meminta dan memberi maaf. Namun sering kali hal positip ini sulit sekali dilakukan saat peristiwa terjadi karena alasan ego masing-masing kedua belah pihak yang menganggap dirinya yang paling benar dan terhormat. Maka momen lebaran ini menjadi saat yang paling tepat untuk ber halal-bihalal (Quraish Shihab : 1996). Dimana saat tersebut manusia terutama umat muslim membuka hati dengan mengakui kesalahan dengan meminta maaf, di pihak lain, rela memberi maaf atau memaafkan. Sikap ini sesuai dengan firman Allah SWT : "(Yaitu) orang-orang yang menafkahkan (hartanya), baik di waktu lapang maupun sempit, dan orang-orang yang menahan amarahnya dan memaafkan (kesalahan) orang. Allah menyukai orang-orang yang berbuat kebajikan" (QS. Ali Imran : 134). Memberi dan meminta maaf dibutuhkan kesiapan mental dan i'tikad baik dari kedua 
belah pihak. Ini memang agak sulit dan merupakan bentuk pengorbanan psikologis yang besar. Maka sesuai hadits para pelakunya akan dibalas dengan pahala dan kenikmatan yang besar yaitu dibuatkan istana dalam surga.

\subsection{Ajaran Kasih (Berbagi).}

Yang terbaik adalah sebanyak yang kita berikan bukan yang kita peroleh ( have much more give not ask), Rasul SAW mengajarkan kita dalam hadits :" kharenunnaasi anfa'uhum linnasi/ sebaik baik manusia yang paling banyak manfaatnya. Syawal yang bermakna meningkat atau peningkatan menjadi momentum tonggak awal mengingatkan kembali untuk meningkatkan dalam berbagai hal kebaikan. Hal yang realistis dalam bulan ini adalah berbagi maaf, dimana sulit rasanya seorang meminta maaf atau mengakaui kesalahan, namun dalam moment lebaran, setiap orang hampir dengan suka rela bahkan ihlas meminta dan memberi maaf kepada sesama.

Berbagi rejeki dalam moment lebaran ini juga menjadi trend. Hampir setiap orang yang berhasil atau memperoleh rejeki lebih setelah bekerja setahun ingin berbagi kepada orang tua, sanak saudara, tetangga yang lebih membutuhkan. Ini adalah kondisi yang baik, dan sesuai dengan ajaran Islam, bahwa dalam setiap rejeki yang kita peroleh ada bagian fakirmiskin dan anak yatim. Ajaran Islam bukan hanya menganjurkan berbagi pada moment lebaran tapi dalam kondisi apapun/susah dan lapang. ( QS. Ali Imran : 134).

\subsection{Berkumpul/bersatu}

Salah satu kebahagian manusia adalah memiliki keluarga yang lengkap, dan mampu menikmati moment kebersamaan.Diantara moment yang tepat tersebut yaitu saat lebaran Idul Fitri, dimana seluruh sanak saudara dan tetangga dekat menyempatkan dan meluangkan waktu untuk berkumpul bersama. jika nilai kebersamaan dan persatuan ini dikembangkan dalam wilayah yang lebih luas seperti satu desa, kecamatan, kabupaten serta negara maka akan tercapailah nilai persatuan dan kesatuan bangsa ( wathon dan basyariah). Karena mencintai bangsa dengan menempatkan persatuan dan persatuan bukan hanya sesuai dengan ajaran Pancasila, juga selaras dengan ajaran agama Islam.

\section{METODOLOGI}

\section{Tujuan Penulisan}

Tulisan ini bertujuan memberi penjelasan kepada pembaca bahwa mudik itu asli budaya Indonesia namun tetap sejalan dengan ajaran Islam dan Islam datang bukan untuk mengikis serta menghancurkan budaya lokal, namun meluruskan dan memperbaiki kembali budaya yang keliru.

\section{Metode Penelitian}

Penelitian ini yuridis normative yang bersifat deskriptif. Metode yang digunakan dengan mengkaji Al-Qur'an dan Hadits serta Sumber data sekunder yang digunakan mencakup bahan hukum primer, bahan hukum sekunder dan bahan hukum tersier. Data yang diperoleh kemudian dipilah-pilah guna memperoleh pasal, ayat dan hadist yang berkaitan dengan kaidah hukum yang kemudian dihubungkan dengan permasalahan yang dihadapi dan disistematisasikan sehingga menghasilkan klasifikasi yang selaras dengan permasalahan 
dalam penelitian ini. Selanjutnya bahan hukum yang diperoleh diolah secara deduktif kualitatif untuk sampai pada kesimpulan, sehingga pokok permasalahan yang ditela'ah dalam penelitian ini akan dapat dijawab.

\section{KESIMPULAN DAN SARAN \\ Kesimpulan}

1. Mudik dalam perspektif psikologi adalah bagian kebutuhan fisilogis manusia yang harus dipenuhi (Moslow) jika esensi mudik adalah untuk silaturahmi dan melepas rindu dengan keluarga dan sahabat.

2. Kebutuhan mudik sulit terkikis dan belum tergantikan oleh mudahnya alat komunikasi seperti : handphone, telegram, email, sky dan teleconfrence.

3. Mudik lebaran asli tradisi dan budaya Indonesia, namun ada beberapa negara yang memiliki kesamaan dengan mudik seperti : China, India, Arab Saudi, Turki dan Malasyia.

4. Ensensi nilai-nilai mudik dengan tujuan untuk silaturrahmi (saling meminta dan memaafkan) sejalan dengan syariat Islam.

\section{SARAN}

Mengingat jumlah pemudik semakin meningkat, pemerintah hendaknya memfaslitasi kebutuhan pemudik terutama transportasi darat, laut dan udara demi menjaga kenyamanan dan keselamatan pemudik sehingga akan dapat ditekan jumlah kecelakaan yang memakan korban jiwa.

\section{DAFTAR PUSTAKA}

[1] Sairin, Sjafr. Perubahan Sosial Masyarakat Indonesia. Yogyakarta, Pustaka Pelajar Offset.2002

[2] M. Quraish Shihab, Tafsir Al-Mishbah, Volume 2, Lantera Hati, Cet ke 10, 2007.

[3] Arie Sudjito, Mudik Lebaran,Yogyakarta, Gajah Mada, 2012.

[4] M. Quraish Shihab, Membumikan Al-Qur'an, Penerbit Mizan, Cet ke 12, 1996.

[5] Tim Penyusun Pusat Pembinaan dan Pengembangan Bahasa, Kamus Besar Bahasa Indonesia, Balai Pustaka, Cet ke 4, 1990.

[6] Prof. Dr. M. Yunus, Kamus Mahmud Yunus,tt

[7] Umar Kayam, Seni.Tradisi, Masyarakat, Yogyakarta, Penerbit Pinus, 2002.

[8] https://id.wikipedia.org/wiki/Mudik.

[9] http://aceh.tribunnews.com/2013/08/02/mudik-dalam-perspektif-budaya-dan- syariat. 